\title{
Collective Action as the Material Expression of Opinion-Based Group Membership
}

\author{
Craig McGarty* \\ Murdoch University
}

\section{Ana-Maria Bliuc}

The University of Sydney

\section{Emma F. Thomas}

The Australian National University

\section{Renata Bongiorno}

Murdoch University

In this article, we argue that progress in the study of collective action rests on an increasingly sophisticated application of the social identity approach. We develop the view, however, that the application of this theoretical perspective has been limited by theoretical and empirical difficulties in distinguishing between social categories and psychological groups. These problems have undermined the ability of researchers to correctly specify the collective identities that actually underpin many instances of collective action. As a partial solution to this problem we focus on collective identities based on shared opinion (opinion-based groups). We develop the proposition that much collective action reflects the crystallization or instantiation of opinion-based groups. We also outline an intervention aimed at stimulating commitment to collective action through group-based interaction involving opinion-based group members. We conclude by emphasizing that opinion-based groups tend to be most successful when they present themselves as

* Correspondence concerning this article should be addressed to Craig McGarty, Murdoch University, South Street, Murdoch, Western Australia 6150, Australia [e-mail: c.mcgarty@murdoch.edu.au].

This research was supported under Australian Research Council's Discovery Projects funding scheme (projects DP0343941 and DP0770731). The views expressed herein are those of the authors and are not necessarily those of the Australian Research Council.

839 
being representative or aligned with dominant, positively valued social categories such as nations. First, individuals must have internalized their group membership as an aspect of their self-
concept: they must be selectively identified with the relevant in-group. It is not enough that
others define them as a group, although consensual definitions by others can become, in
the long run, one of the powerful causal factors for a group's self-definition

(Tajfel \& Turner, 1979, p. 41).

(...) I am a feminist first, not a woman, and a socialist first, not a Scot. . . unite with people who share your ideas not your accent [or] your genitals (Harpies \& Quines, quoted by Hopkins, Kahani-Hopkins, \& Reicher, 2006).

In this article, we focus on the potential of the social identity perspective developed by Tajfel, Turner, and their colleagues to provide a unique standpoint to the study of collective action. We suggest that this theoretical tradition has already made great progress in providing a more complete understanding of the nature of the collectives that take collective action and that this contribution has already been deep and significant.

We also argue, however, that some of the theoretical potential of the social identity perspective has been compromised by the operational inability of social identity researchers to pursue the theoretical distinction between social categories and groups. This is a widespread problem, but there is possibly no domain where it is more limiting than in the study of collective action. The reason for this is deceptively simple. If we fail to understand the nature of the collectives in collective action we will inevitably fail to understand collective action. We suggest that the social identity perspective can avoid these problems by recognizing that much collective action is not so much by social categories but about or on behalf of social categories. In this article, we also seek to clarify the nature of the collectives involved in taking collective action through our focus on opinion-based groups. Indeed the quote above passed on through the work of Hopkins et al. (2006) anticipates our argument very neatly. We argue that people form common cause with others by forming groups based on shared opinions, despite expectations that they should organize around social categories.

In developing these points we follow the lead of Hopkins and Reicher (1997) that collective action stems from category definition. In doing so we believe we are contributing to filling a gap that has been identified by Reicher, Cassidy, Wolpert, Hopkins, and Levine (2006):

In the case of helping, then, we might expect that those who wish to create social movements in favour of intervention might do so, firstly, by constructing social categories in such a way that victims and potential helpers form a single ingroup and/or, secondly by constructing norms in such a way that humanitarian action is a central tenant of the group... The implication is that... helping is something that can be actively created through argument. It is something that can be publicly mobilized. (p. 53) 
The first of the alternatives raised by Reicher et al. has received considerable attention through work on common in-group identity (e.g., Dovidio et al., 1997; Gaertner \& Dovidio, 2000, 2005). The idea that cooperation stems from inclusive category membership can be considered as social psychology's longstanding solution to this problem (McGarty, 2006; though it is important to note the burgeoning array of dual-identity alternatives to the superordinate approach; e.g., Eggins, Haslam, \& Reynolds, 2002; Hornsey \& Hogg, 2000; Mummendey \& Wenzel, 1999). A key thrust of our article is to develop our own take on Reicher et al.'s second option of understanding how constructing norms makes action a central tenet of the group.

From our discussions we are aware that many researchers who adopt the social identity perspective have an excellent understanding of the distinction between social categories and groups that we are going to labor in this article. We would concede that the problem that we address here is not one that has been created by scholars working in the field of collective action but one that has been imported from other fields of the social psychology of intergroup relations. We are concerned, however, that the imprecision that we want to address has starker negative consequences in the field of collective action than it does in some other areas. The most positive construction that can be placed on our contribution is that we are encouraging researchers to go further in a direction in which they have already made great progress.

\section{Distinguishing between Groups and Social Categories}

To pursue our first point we need to enter a very old debate that may seem somewhat abstract but nevertheless promises some general practical benefits. Researchers have long entertained a distinction between in-groups and out-groups, and the conventional wisdom for most of social psychology's history has been that in-groups reflect categories that the perceiver belongs to and out-groups represent categories to which they do not.

In our view this categorical definition of in-groups, derived from Summer (1906) lies at the heart of the problem. Social identity researchers have adopted a contemporary theory that incorporates a subjective and dynamic definition of the group, but they too often uncritically accept a definition of the in-group that is based on objective and static social categories.

Most treatments assume that nominal social category memberships and subjective group memberships are one and the same. That is, it is assumed that a person's in-groups are identical to the social category memberships regardless of their subjective identification. Thus men might be said to represent an out-group for women and women are an out-group for men. The same might be said about Blacks and Whites or Muslims and Jews. 
It is easy to see the appeal of this simple equation but the problem with it becomes obvious when we consider Turner's (1982) definition of a social group: "a social group can be defined as two or more individuals who share a common social identification of themselves or, which is nearly the same thing, perceive themselves to be members of the same social category" (p. 15, emphasis added).

This is the definition that seems to be accepted by most social identity researchers. This definition laid the foundations for self-categorization theory with its emphasis on variable, flexible, and context-dependent self-perception. Contrary to the view imported from Summer (1906) a social category cannot be an in-group until the perceiver recognizes that that category is an aspect of self at that particular time. It makes no sense under this definition for other people to specify your group memberships.

Turner's definition is thus completely incompatible with an approach that assumes that group memberships are invariant aspects of social structure. The incompatibility emerges most starkly in the analysis of collective action where we are forced to consider the nature of the collectives that act and to consider the ways in which common causes come to exist between people with different social category memberships.

However, Turner, Hogg, Oakes, Reicher, and Wetherell's (1987) selfcategorization theory articulates the conceptual tools they intended to solve the problems raised here and should have overcome that confusion. Hypothesis 4 of self-categorization theory is "That psychological group formation takes place to the degree that two or more people come to perceive and define themselves in terms of some shared ingroup-outgroup categorization" (Turner et al., 1987, p. 51).

Thus, according to self-categorization theory, group membership is intensely subjective. People do not become part of a group until they feel they are part of that group. Mere membership of a social category cannot constitute an in-group membership unless the perceiver is subjectively identified with that category. The theory expands on this requirement by specifying that those social identifications must also be shared with others.

Self-categorization theory is a theory of dynamic self-perception that seeks to explain how people can act as individuals at some times and in terms of any one of an endless number of different group memberships at other times. The theory explains these variations in perspective in terms of the construct of category salience. As particular (social) categories become salient (i.e., switched on or activated) people are expected to act in terms of the social identities associated with those categories.

Before going further we need to note some caveats. A number of scholars, especially Spears, Ellemers, and Doosje (e.g., Doosje, Spears, \& Ellemers, 2002; Ellemers, Spears, \& Doosje, 1997) have very seriously followed the argument by Tajfel and Turner (1979) that intergroup differentiation (and related phenomena) 
will be qualified by subjective group membership identification. Predictably, given the view we have presented so far, we endorse this concern. However we would also caution that social identification or commitment to a group membership does not fully capture the degree to which self-categorization qualifies action. As we will argue below, we think the problem is not only that there is variation in social identification across members of a social category, but also that we do not always measure identification with the relevant category. In the tradition of research on collective action, the point that commitment to a cause is a critical determinant of support for action is also strongly evident in the work of Klandermans and colleagues (de Weerd \& Klandermans, 1999; Klandermans, 2000; Klandermans, Sabucedo, \& Rodriguez, 2002) on the social identification route to collective action, in Simon and colleagues' (Simon et al., 1998; Simon, Stürmer, \& Steffens, 2000; Stürmer \& Simon, 2004) work on activist identity and in their joint work (Simon \& Klandermans, 2001) on politicized collective identity.

The other key caveat is that we fully accept that social categories, where they represent aspects of social structural relations, are likely to continue to be psychologically consequential, even where they do not form the basis for the salient group membership. Indeed work by Bongiorno and David (2008) suggests that there are excellent reasons why certain social categories (such as gender) function as categories rather than group memberships in a range of situations. Thus, an unintended benefit of the category-group confusion is that by ignoring the subjective aspects of group memberships, many social psychologists have incorporated social structural variables such as gender, ethnicity, class, and nationality into their analyses.

Those points notwithstanding, the problem of equating social categories and group memberships remains particularly marked when we consider collective action. We think this is because collective action frequently involves action that is about relations between social categories, is taken by members who span those categories, and perhaps most importantly, often takes place under circumstances where there is intense contestation within those categories.

It is useful to illustrate these points with two examples. Very widespread collective action was taken by opponents of the U.S.-led invasion of Iraq in 2003. Focus for a moment on participants in this protest action drawn from the United States, Britain, and Australia (the Western democracies that took part in the initial invasion). There is no political, institutional, religious, ethnic, or social category that binds these people together. One thing that the protesters may have had in common was a national sense of responsibility (e.g., that it was wrong for their nation to invade another country without the full authorization of the United Nations), but even the most casual observers would have noted that ownership of the national identity was hotly contested in this context (in very much the way that Reicher et al., 2006, have argued). Opponents of the invasion were derided by people with opposite views as being disloyal to their own nation and as lending 
comfort to the regime of Saddam Hussein. We need other collective identities to explain these contested movements and evidence of mechanisms for contestation within the movement whereby different emotions lead to different action strategies (see Iyer, Schmadel, \& Lickel, 2007).

Industrial action shows similar levels of contestation. It might be convenient to understand the identity dynamics in that domain as involving conflicts between workers and bosses or union and management, but real-life contexts are more subtle. Industrial action is taken by workers (sometimes including people who are not members of a union) because they support a cause and industrial action can be vociferously opposed by union members and other workers (see Taylor \& McGarty, 2001).

\section{Identity Alternatives for Explaining Collective Action}

What are the current options for explaining collective action in social identity terms? Put another way, if collective action is genuinely collective, then what are the collective identities involved?

A dominant account that has been widely deployed relies on social category and institutional identities. In an excellent exposition of the social identity approach to social movement participation, Stürmer and Simon (2004) observe that:

Social movements often, if not typically, build on pre-existing collective identities. These derive from membership in a disadvantaged group (e.g., collective identity as labourer, woman, member of a particular ethnic or religious identity, as a gay man or a lesbian woman) or from membership in more exclusive political groups and organizations actively promoting social change on behalf of the disadvantaged in-group (e.g., collective identity as a trade unionist, a feminist, or a minority rights advocate). (p. 68)

A good example of the general approach described by Stürmer and Simon is the paper by de Weerd and Klandermans (1999). These authors explored the social identification and collective action intentions of Dutch farmers (in their terms a disadvantaged "group" but what we would prefer to call a social category). Their most important finding for our purposes was that the correlation between identification with the social category and the degree to which the farmers intended to take part in protest action to support their cause was weak. Kelly and Breinlinger (1995) obtained similar findings for gender categories in earlier research. The extent to which women identified with the category "women" was a weak predictor of intentions to take protest action. Most compellingly, Simon et al. (1998) found in a range of contexts, that identification with social category memberships (gay people, older people, and overweight people) was weakly correlated with intentions to take action.

These findings are important in relation to our argument as they suggest that, in order to better understand collective action, it is necessary to explore identification with more specific categories which are relevant in the context of action, rather than 
broader social categories. Activist identities seems to get closer to the core of the issue of collective action, by offering a more direct route to predicting intentions to take or become involved in collective action. Indeed both Kelly and Breinlinger (1995) and Simon and colleagues (1998) found that the correlations were stronger when identification with broader categories was replaced by identification with an activist identity.

However we believe that activist identities are profoundly limited by their subjective applicability. Activists are rare and mass movements (by definition) involve large numbers of people who mostly do not fall into the activist category. The problem here is not so much that most movement participants are weakly identified as activists but that the vast majority of participants would avidly reject such a label. That is, the participants are not so much activists as supporters of that cause.

Simon and colleagues have developed two solutions to this problem building on the work of Klandermans (1997). The first, as articulated in the work of Stürmer and Simon (2004), is to focus on identification with a movement. We agree that this is a positive development, but it is also limited. Many of the collective forces in society are conservative, and with the exception of explicitly reactionary ones, they are not movements because they are not going anywhere. Given Stürmer and Simon's focus on collective action (rather than inaction) this omission is fair for tactical reasons; but, in our view, it risks missing some of the bigger picture. A related positive contribution is the idea of politicized collective identity (Simon \& Klandermans, 2001). We agree that to the extent that people become aware of shared grievances, and understand that these grievances can be addressed by influencing other members of society, they will come to develop a form of identity that incorporates explicit motivations to engage in a struggle for power. Our concern here is that we agree that politicization may be sufficient to promote collective action but it may not be necessary.

This point needs some elaboration. We argue that much collective action does indeed stem from well-developed political identities based on ideological engagement and contestation, but there are other domains where collective action is relatively spontaneous and involves group formation around causes that are political only in a minimal sense. The members of a group of residents who protest over the closure of a local library, or a group of students who protest over a change of examination format, may have developed a politicized collective identity but this seems hard to justify when we consider the rapidity with which such protests can emerge and the fact that such protests can emerge within tiny pockets of a community (e.g., within a particular street or a particular classroom). It seems difficult to claim that such local activists have developed a consciousness (as a resident or student) based on shared grievances before they take action (though again we stress that we have no doubt that such a consciousness will positively contribute to the commitment to change). 
Some might be tempted to dismiss such everyday instances of dissent and protest as being trivial. This is a judgment of degrees, but in our view it would be a mistake to fail to see these phenomena as resting on collective processes. Thus we see great merit in the ideas of identification with social movements and of politicized collective identity. We believe both concepts are phenomenologically and subjectively valid, but we argue that both concepts are limited by the same constraint. They do not easily allow us to consider cases where members from different social categories (or what Simon \& Klandermans, 2001, term "reallife social groups") come together to form common cause, and in particular where members of high-status "groups" work to overcome the disadvantage of others. As Duncan and Stewart (2007) observe in relationship to activism for gay rights and against racism: "individuals develop collective identities based not solely on their position in the social structure (as straight or white), but based on their analysis of the damage done by that social structure." Perhaps more importantly, previous approaches also fail, in our view, to capture the dynamics of deep division within disadvantaged or otherwise aggrieved social categories that provides a backdrop for collective action.

To return to the domain studied by Kelly and Breinlinger (1995) we would argue that identification with women is a weak predictor of action intentions to advance the cause of women because of political contestation within that category. Feminists may very well have developed a politicized collective identity whereas "traditional" women may reject this. Again the issue is not that the antifeminists are weak female identifiers, or that they have somehow failed to develop a politicized gender identity (a factor that Duncan \& Stewart, 2007, show to be an excellent predictor of political participation). On the contrary, such antifeminists may even be highly identified with a cause that has the aim of defeating feminism.

For these reasons and others we believe that there is space to pursue alternatives to complement these ideas. We now turn to our preferred alternative.

\section{The Opinion-Based Group Alternative}

Opinion-based groups are psychological groups in the sense used by Turner (1982) but have a social identity defined by a shared opinion (see Bliuc, McGarty, Reynolds, \& Muntele, 2007). Merely holding the same opinion as others is not sufficient for such a group to be said to exist, rather the shared opinion needs to become part of that social identity. In this way, people can come to perceive and define themselves in terms of their opinion group membership in the same way as they would with any other psychologically meaningful social category or group. Where the opinion-based group membership becomes switched on, group members should behave in line with the norms of that group.

Opinion-based groups are particularly relevant for understanding collective action for a number of reasons. Firstly, they often form around controversial 
issues, and oppositionally defined opinion-based groups tend to champion opposing perspectives on key issues. In other words, there are opinion-based groups that aim to change the social world in some way and, on the contrary, groups which aim to preserve the status quo.

Opinion-based groups can be readily distinguished from social categories and action groups. Opinion-based groups can often be formed within a broader social category (or be more broad than a social category). One important idea in relation to opinion-based groups is that they are often formed about the relations between social categories or groups, or on behalf of those social categories or groups. This is the case with feminist and antifeminist opinion-based groups, which are groups formed around ideologies about relations between social categories based on gender. In this way, opinion-based groups can also help to restructure problematic intercategory boundaries. It is easier for women and men to work together to promote gender equality, or for people of different races to work to promote tolerance and acceptance, if members of both categories share a relevant opinionbased group membership.

Opinion-based groups can also be distinguished from action groups. Most action groups are in fact based on shared opinions and opinion-based groups can be seen as incipient action groups. Specifically, activist groups can be considered as emerging from opinion-based groups. The "single-issue pressure groups" studied by Kelly and Breinlinger (1995) and the activist groups such as Gray Panthers, gay movement, AIDS volunteer service organization, and fat acceptance movement investigated by Simon et al. $(1998,2000)$ and Stürmer, Simon, Loewy, and Jörger (2003), can be regarded as directly emerging from opinion-based groups. They all represent the active, strongly committed, and organized faction of a broader opinion-based group. All members of an opinion-based group may have the potential to take spontaneous collective action in specific circumstances, but only a small fraction of the membership will be involved in organizing it.

In other ways, the idea of opinion-based groups involves a return to themes developed earlier by Klandermans and Oegema (1987) and Oegema and Klandermans (1994). These authors suggested that action mobilization involves four phases (1) becoming sympathetic to a cause (or part of the mobilization potential for a cause), (2) becoming a target for mobilization attempts, (3) becoming motivated to participate, and (4) overcoming barriers to participation. Arguably, opinion-based groups capture a similar idea to Klandermans and Oegema's (1987) concept of mobilization potential (the first stage of the model). These authors define mobilization potential as "those who take a positive stand towards a social movement" which they then equate with Kriesi's concept of manifest political potential, which they describe as "a group of people with a common identity and a set of common goals." As social movement formation proceeds down the steps identified by Klandermans and Oegema, it seems plausible that politicized collective identity as described by Simon and Klandermans (2001) will become 
increasingly relevant but we would argue that to understand the political cleavages at the incipient stage of action, then other identities that recall Kriesi's ideas seem highly relevant.

Opinion-based groups, when compared to groups based on social categories, do tend to be easy to connect to group normative behaviors. This is because opinion-based group membership hinges on consensus between members that imply certain courses of action and rules out other alternative actions. As Kelly and Breinlinger (1995) showed, being a woman does not imply a particular stance on gender equality, but we would argue that membership of a feminist opinionbased group will tend to imply much clearer stances and courses of action.

Our research (e.g., Bliuc et al., 2007) conducted in Australia and Romania shows that identification with a political opinion-based group is an excellent predictor of intentions to take politically relevant behavior. Our strongest claim is that to talk of collective action is to talk of opinion-based groups in action. In other words, collective action is the material crystallization or expression of the existence of salient opinion-based group memberships. Work by Musgrove and McGarty (2008) also suggests that opinion-based group memberships about the war on terror are excellent predictors of contrasting group-based emotions and actions (cf. McGarty et al., 2005, who found weak evidence for such relationships with national identification; see also McGarty \& Bliuc, 2004).

Collective action is strongly linked to opinion-based group identity for a number of reasons. First, opinion-based groups are formed primarily to convert broad ideologies or affinities into collective action. Unified social action is aimed either to create social change or to preserve the status quo. Building on social identity (Tajfel \& Turner, 1979) and Klandermans' (2000) ideas, such action is taken by people who share an opinion about achieving or rejecting social change. Depending on the opinion they hold, they can be considered to be members of one opinion-based group or another (e.g., pro- or antichange of the status quo).

As intimated earlier, activist groups can be seen as organized subcategories of larger opinion-based groups or as factions organized to act in terms of a certain subjective opinion-based group membership. Thus, in terms of relevance to action, broad social categories should be the least relevant, with opinion-based group representing the missing link between them and activist groups. In order to understand the mechanisms and links between collective identities and action, it is essential to look at the underlying nature of collective action and of the groups participating in collective action.

Thus, activist identities can be considered to be opinion-based group identities that are aligned with organizations constituted on the basis of opinion-based group membership, with rules and a structure designed to promote a certain stance or view of the world. In other words, activist identities are opinion-based group identities which have achieved a more objective consistency and which take responsibility for more organized forms of collective action. In the case of 
spontaneous collective action, opinion-based groups may appear in a raw, less structured form. Participants in action need not be attached to specific activist groups but simply share a common understanding and stance on a certain issue and hence come to share an opinion-based group membership. In the next section we explore how these understandings and stances can come to be shared and intensified.

\section{Sharpening Opinion-Based Group Memberships through Group-Based Interaction}

In a very perceptive chapter, Wright and Lubensky (2008) observe that prejudice reduction interventions have the potential to demobilize collective action. This is a subtle point. Blurring or invalidating category boundaries (e.g., "color blindness") can undermine efforts by members of disadvantaged groups to work together to overcome injustice. Indeed affirmative action policies are often challenged by White Power advocates (and others) on the grounds that they involve racial discrimination (against whites).

Motivated in part by Wright and Lubensky's concerns, we have adopted a new approach to the problems of reducing prejudice and promoting commitment to positive social change. In doing so, we also acknowledge that previous interventions may have had limited success because they are attempts to achieve an extremely difficult goal. It may be unproductive to attempt to change the opinions of people who already have hostile or negative attitudes toward disadvantaged or stigmatized groups. Our work instead explores the possibility of boosting commitment to oppose prejudice among people who are already, at least nominally, opposed to it. Our reasoning is that such bolstering of commitment amongst otherwise mildly committed people can serve to empower them on the path toward active opposition to prejudice. Where ordinary people become increasingly committed to talking and acting in line with antiprejudiced norms, they should also be more likely to confront racism when they encounter it.

Indeed, by using the concept of the opinion-based group, we have designed an opinion-based group interaction method that our ongoing research suggests provides us with an effective way to energize and sharpen peoples' commitment to engage in collective action. Our intervention, which is inspired by work on group decision making and polarization (in particular Lewin, 1947; Postmes, Spears, Lee, \& Novak, 2005) involves recruiting participants for a study to discuss a certain issue (say attitudes to Reconciliation between Indigenous and non-Indigenous Australians). Privately, participants are asked to specify a relevant opinion-based group membership, for example, whether or not they consider themselves to be supporters of efforts to promote Reconciliation.

Participants assigned to experimental conditions are then asked to take part in a group discussion with other nominal supporters. The discussion takes the form 
of a planning session where participants are asked to reach agreement on ways to achieve the goals of this movement. They are told that their written deliberations will be included in (variously) a web site to be hosted by the School of Psychology, a letter to a responsible authority, or an article to be submitted to a campus or community newspaper. The groups are given around 30 minutes to complete the discussion and to note down their agreed positions. They are then measured on a series of items capturing relevant beliefs, emotional and action intentions, and measures of social identification. Responses are compared with participants who have been randomly assigned to a (no interaction) control condition.

The method is designed to energize action by giving participants the opportunity to articulate norms of action in a way that is validated both through the development of consensus within the group and because it is considered to be part of real and legitimate efforts to create that social change. The method also adds to the tool kit of social psychological research in that, through group-based interaction, we are able to observe processes of consensus and dissensus which are likely to be highly analogous to what would occur in everyday settings when people talk to others about a particular issue and become galvanized to engage in collective action. Indeed, the group-based interaction technique has been effective in improving attitudes to people with mental disorders and Australian Aborigines (Blink, 2005, unpublished data; Gee, Khalaf, \& McGarty, 2007) and bolstering commitment to combat poverty in developing countries (Thomas \& McGarty, 2009) and more recently in promoting commitment to combat climate change (Bongiorno, McGarty \& Kurz, 2009, unpublished data).

Importantly, we are not suggesting that merely bringing people into a room to discuss an issue of mutual interest or importance will change their attitudes in positive and lasting ways. We have observed that introducing such discussion as part of a routine class activity has no effect of itself. This was further borne out in research by McGarty et al. (2008, Study 1) who showed that in conditions where the experimenter presented herself as someone who was uncommitted to the aims of the movement and more interested in gathering data for a research project, the positive effects of the interaction were negated.

Our general impression of the method is that it tends to be successful in promoting change when the groups agree about the overall direction that the cause needs to take, perceive the process as a legitimate activity for the opinion-based group, and find the experience of the group-based interaction to be validating and positive. We think that the overlap with Klandermans and Oegema's (1987) first three steps in action mobilization process is because we have created an analogue of processes that frequently occur in community centers, church halls, bars, and other locations.

While results have suggested that there are some elements which will undermine and "switch off" the opinion-based group interaction, we have also identified some key processes which we believe work to enhance the opinion-based group 
interaction. We draw on work by van Zomeren, Spears, Leach, and Fischer (2004), who identified two potentially important variables in motivating collective action. Their dual-pathway model suggests that people will take action when they feel a relevant group-based emotion (such as anger or outrage at a perceived injustice) and/or when they believe that their actions will be effective (collective efficacy, following Bandura, 2000). In the context of opinion-based groups and collective action more generally, it is clear that where groups experience feelings of pity for the disadvantaged, or do not believe that their actions will make any difference to their cause, these groups are unlikely to be galvanized to act (or, at least, not in a way designed to bring about positive social change).

We investigated the interplay of emotion (particularly outrage), efficacy, and opinion-based group identities in the context of the group-based interaction, reasoning that both emotion and efficacy processes were likely to be implicated in the group-based interaction, in different ways. Emotions, and expressions of emotion, may play a particularly important role in collective action, because of the ease with which they are communicated, and the strong motivational base they can provide (Leach \& Tiedens, 2004). The statement that, for example, "the situation makes me angry" conveys a large amount of information about how a person feels about the situation, his or her attributions for responsibility, and even the physiological sensations that accompany the experience. As such, shared emotion might play a useful coordinating role in the context of the opinion-based group interaction, in so much as it implies a shared understanding of the world.

Consistent with this argument we find that when groups are given a specific emotion norm (in this case outrage) to incorporate in their planning session and to consensualize around, this boosts mean levels of commitment to action, outrage and identification with the opinion-based group, over and above the standard effects of the opinion-based group interaction method (Thomas \& McGarty, 2009). This suggests that where outrage is taken on, as a shared, meaningful norm for that particular opinion-based group, it is able to energize action, perhaps because this outrage norm effectively replaces potentially demotivating emotion. For example, it becomes antinormative for a member of this opinion-based group to feel pity as it becomes normative for them to feel outraged at the situation.

Similarly, we would expect efficacy processes to be implicated in the opinionbased group interaction, just as they would seem to be in real-life opinion-based groups contemplating collective action. Given that the nature of the task is to discuss practical solutions for overcoming the disadvantage, we would expect this process to boost efficacy beliefs. And indeed, we do find evidence that where groups are able to work effectively and come up with strategies to work to overcome the disadvantage, this does boost efficacy beliefs. Conversely, as indicated above, where efficacy is undermined, or groups consensualize around a demotivating emotion norm, the effects of the intervention seem likely to be undermined. 
Thus we find that the group-based interaction leads to significant boosts in commitment to take action to overcome disadvantage under conditions where participants (1) endorse, and consensualize around a shared understanding that it is appropriate to feel outraged at the situation and (2) are effectively able to come up with strategies to do something about it, which boosts efficacy beliefs. While this seems to be the case in the context of the opinion-based group interaction, it is worth noting the intriguing possibility that there may be other ways to align opinion-based group identification, emotion, and efficacy to produce shifts in commitment to take action.

The opinion-based group concept, in conjunction with the group interaction method, is a very useful tool for studying the processes by which real-life opinionbased groups come to take action or refuse to do so. We do caution though that while our research has concentrated on the promise of the method for understanding and promoting positive social change, it is likely that similar processes operate in more sinister instantiations of negative and destructive collective action (Smith \& Postmes, 2009).

\section{Problems with and Prospects for the Opinion-Based Group Formulation}

Before concluding this article, we wish to address some of the problems and prospects of the opinion-based group formulation. We believe that the approach has some distinctive virtues. We have argued in some detail that the idea of opinion-based group membership can complement the progression that is evident in the field of collective action toward a clearer specification of identity dynamics. The opinion-based group formulation allows a theoretical solution to the problem of common cause.

The question arises as to what role the broad social categories serve in collective action. These are by no means irrelevant, and indeed our motivation for seeking to differentiate them from subjectively functioning group memberships is precisely because they are important. Let us be clear then that we are certain that social and institutional categories such as ethnicity, gender, class, nation, region, religion, and organizational membership can provide platforms for collective action, but that these memberships tend to be poorly served for taking action. Nevertheless as visible aspects of the self there is every reason to believe that these categories will be deployed, but in ways that are less likely to take the form of collective action unless they are accompanied by opinion-based group formation.

Nevertheless we believe that social categories will have tangible political consequences to the extent that opinion-based groups are able to align themselves with social categories. Indeed we go so far as to develop the argument elsewhere (Bliuc, McGarty, Hartley, \& Muntele, 2008; Hartley, McGarty, \& Donaghue, 2008) that the political success of an opinion-based group rests largely on the degree to which that group is able to align itself with some positively valued social category, 
that is, to the extent that membership of the opinion-based group comes to stand for or represent the broad social category (see Mummendey \& Wenzel, 1999). Perhaps the clearest examples are provided by political parties that successfully align themselves with a national or regional identity so that their opinions are attributed broadly to virtually all members of a category. In this way, the social category may be reunited with the group in a way that is compatible with Simon and Klandermans' (2001) analysis.

To be sure social categories have powerful consequences even when they are not engaged as group memberships. They reflect social structure and relations and provide alternative categorizations. There are inevitable sensitivities and limits on members of advantaged social categories who seek to engage in collective action alongside members of disadvantaged social categories. What does it mean to be a male feminist or a white civil rights activist? These are not unproblematic or uncontested identities but our point is that they are possible identities and when salient they can have consequences that need to be understood.

There is also the question of why the opinion-based group idea is superior to the strategy of stressing superordinate group membership. This is a matter that one of us has addressed in some detail elsewhere (McGarty, 1999, 2006). McGarty argues that, contrary to self-categorization theory, there is limited evidence that the self (or for that matter other systems of categories) is hierarchically organized (as a tree structure) and that people do not use hierarchies for reasoning, even when they are presented with hierarchically organized categories. The problem becomes more acute for social categories given the inevitable containment and overlap relations. Are categories such as male and female subordinate to national categories such as Australian and American? Is not the opposite equally plausible?

This technical argument aside, we believe that opinion-based group memberships are not reducible to superordinate category memberships. Opinion-based groups can be more or less abstract or inclusive than other categories and therefore they cannot be equated with superordinate categories. Furthermore, to the extent to which superordinate categories are subjectively valid at some point of time (and we do not dispute that they can be) the content of those categories will be constrained to some degree by the relatively invariant features of social reality. As Wright and Lubensky (2008) explain in some detail, identification with superordinate categorizations may serve to reinforce the inferior status of disadvantaged group members. Opinion-based group membership can, but need not, fall victim to the same trap.

\section{Conclusion}

Our justification of our approach has necessarily been critical of the work of many scholars whose work we greatly admire. We do not seek to back away from that criticism in our conclusion except to say that we see the concept of the 
opinion-based group as complementing and extending the work that has established the value of the social identity approach. In particular, we believe that our approach carries to the next logical step a process that is inevitably set in motion by the work of Simon and Klandermans (2001), of Wright (2001), and of Hopkins and Reicher (1997).

If this logical thread can be expressed in a single sentence then it is the idea that collective action must be connected to ideas, and that political action must be connected to ideology, and all of these things, action, ideas, and ideology must be tied to collective identity. In recent years, social psychology has struggled to grapple with ideology in a way that is compatible with collective identity (many preferring to consider it as an expression of individual orientations): opinionbased groups represent one way in which the ideological aspects of society can be understood in collective terms.

\section{References}

Bandura, A. (2000). Exercise of human agency through collective efficacy. Current Directions in Psychological Science, 9, 75-78.

Bliuc, A.-M., McGarty, C., Reynolds, K., \& Muntele, D. (2007). Opinion-based group membership as a predictor to commitment to political action. European Journal of Social Psychology, 37, $19-32$.

Bliuc, A.-M., McGarty, C., Hartley, L., \& Muntele, D. (2008). Conservative opinion-based groups and collective action. Unpublished manuscript, The University of Sydney.

Bongiorno, R., \& David, B. (2008). The status of gender in psychology: Basic primary category, variable self-category, or something in between? Unpublished manuscript, The Australian National University.

de Weerd, M., \& Klandermans, B. (1999). Group identification and social protest: Farmer's protest in the Netherlands. European Journal of Social Psychology, 29, 1073-1095.

Doosje, B., Spears, R., \& Ellemers, N. (2002). Social identity as both cause and effect: The development of group identification in response to anticipated and actual changes in the intergroup status hierarchy. British Journal of Social Psychology, 41, 57-76.

Dovidio, J. F., Gaertner, S. L., Validzic, A., Matoka, K., Johnson, B., \& Frazier, S. (1997). Extending the benefits of recategorization: Evaluations, self-disclosure and helping. Journal of Experimental Social Psychology, 33, 401-420.

Duncan, L. E., \& Stewart, A. J. (2007). Personal political salience: The role of personality in collective action and identity. Political Psychology, 28, 143-164.

Eggins, R. A., Haslam, S. A., \& Reynolds, K. J. (2002). Social identity and negotiation: Subgroup representation and superordinate consensus. Personality and Social Psychology Bulletin, 28, $887-899$.

Ellemers, N., Spears, R., \& Doosje, B. (1997). Sticking together or falling apart: In-group identification as a psychological determinant of group commitment versus individual mobility. Journal of Personality and Social Psychology, 72, 617-626.

Gaertner, S. L., \& Dovidio, J. F. (2000). Reducing intergroup bias: The common ingroup identity model. New York: Psychology Press.

Gaertner, S. L., \& Dovidio, J. F. (2005). Understanding and addressing contemporary racism: From aversive racism to the common ingroup identity model. Journal of Social Issues, 61, 615-639.

Gee, A., Khalaf, A., \& McGarty, C. (2007). Using group-based interaction to change stereotypes about people with mental disorders. Australian Psychologist, 42, 98-105.

Hartley, L., McGarty, C., \& Donaghue, N. (2008). What to do after saying sorry? Understanding the enabling conditions for commitment to political action about reconciliation in Australia. Unpublished manuscript, Murdoch University. 
Hopkins, N., \& Reicher, S. (1997). Social movement rhetoric and the social psychology of collective action: A case study of anti-abortion mobilization. Human Relations, 50, 261-286.

Hopkins, N., Kahani-Hopkins, V., \& Reicher, S. D. (2006). Identity and social change: Contextualizing agency. Feminism and Psychology, 16(1), 52-57.

Hornsey, M. J., \& Hogg, M. A. (2000). Assimilation and diversity: An integrative model of subgroup relations. Personality and Social Psychology Review, 4, 143-156.

Iyer, A., Schmader, T., \& Lickel, B. (2007). Why individuals protest the perceived transgressions of their country: The role of anger, shame and guilt. Personality and Social Psychology Bulletin, $33,572-587$.

Kelly, C., \& Breinlinger, S. (1995). Identity and injustice: Exploring women's participation in collective action. Journal of Community and Applied Psychology, 5, 41-57.

Klandermans, B. (1997). The social psychology of protest. Oxford: Basil Blackwell.

Klandermans, B. (2000). Identity and protest: How group identification helps to overcome collective action dilemmas. In M. Van Vugt, M. Snyder, T. Tyler, \& A. Biel (Eds.), Cooperation in modern society: Promoting the welfare of communities, states and organizations (pp. 162-183). London: Routledge.

Klandermans, B., \& Oegema, D. (1987). Potentials, networks, motivations and barriers: Steps towards participation in social movements. American Sociological Review, 52, 519-531.

Klandermans, P. G., Sabucedo, J. M., \& Rodriguez, M. (2002). Identity processes in collective action participation: Farmer's identity and farmer's protest in the Netherlands and Spain. Political Psychology, 23, 235-251.

Leach, C. W, \& Tiedens, L. Z. (2004). Introduction: A world of emotion. In L. Z. Tiedens \& C. W. Leach (Eds.), The social life of emotions (pp. 1-16). Cambridge: Cambridge University Press.

Lewin, K. (1947). Group decision and social change. New York: Holt, Rinehart \& Winston.

McGarty, C. (1999). Categorization in social psychology. London: Sage.

McGarty, C. (2006). Hierarchies and groups: The roles of salience, overlap, and background knowledge in selecting meaningful social categorizations from multiple alternatives. In R. J. Crisp \& M. Hewstone (Eds.), Multiple social categorization: Processes, models and applications (pp. $25-$ 49). Hove, UK: Psychology Press.

McGarty, C., \& Bliuc, A.-M. (2004). Collective guilt in Australia. In B. Doosje \& N. R. Branscombe (Eds.), Collective Guilt: Antecedents, correlates and consequences (pp. 112-129). Cambridge: Cambridge University Press.

McGarty, C., Pedersen, A., Leach, C. W., Mansell, T., Waller, J., \& Bliuc, A.-M. (2005). Groupbased guilt as a predictor of commitment to apology. British Journal of Social Psychology, 44, $659-680$.

McGarty, C., Bongiorno, R., Blink, C., Thomas, E. F., \& Kurz, T. (2008). Opinion-based group interaction: An experimental model for exploring social change. Unpublished manuscript, Murdoch University.

Mummendey, A., \& Wenzel, M. (1999). Social discrimination and tolerance in intergroup relations: Reactions to intergroup difference. Personality and Social Psychology Review, 3, 158-174.

Musgrove, L., \& McGarty, C. A. (2008). Opinion-based group membership as a predictor of collective emotional responses and support for pro- and anti-war action. Social Psychology, 39, 37-47.

Postmes, T., Spears, R., Lee, A. T., \& Novak, R. J. (2005). Individuality and social influence in groups: Inductive and deductive routes to group identity. Journal of Personality and Social Psychology, $89,747-763$.

Oegema, D., \& Klandermans, B. (1994). Why social movement sympathizers don't participate: Erosion and nonconversion of support. American Sociological Review, 59, 703-722.

Reicher, S., Cassidy, C., Wolpert, I., Hopkins, N., \& Levine, M. (2006). Saving Bulgaria's Jews: An analysis of social identity and the mobilisation of social solidarity. European Journal of Social Psychology, 36, 49-72.

Simon, B., \& Klandermans, B. (2001). Politicized collective identity: A social psychological analysis. American Psychologist, 56, 319-331.

Simon, B., Loewy, M., Stürmer, S., Weber, U., Freytag, P., Habig, C., et al. (1998). Collective identification and social movement participation. Journal of Personality and Social Psychology, $74,646-658$. 
Simon, B., Stürmer, S., \& Steffens, K. (2000). Helping individuals or group members? The role of individual and collective identification in AIDS volunteerism. Personality and Social Psychology Bulletin, 26, 497-506.

Smith, L. G. E., \& Postmes, T. (2009). Intra-group interaction and the development of norms which promote inter-group hostility. European Journal of Social Psychology, 39, 130-144.

Stürmer, S., \& Simon, B. (2004). Collective action: Towards a dual-pathway model. European Review of Social Psychology, 15(1), 59-99.

Stürmer, S., Simon, B., Loewy, M., \& Jörger, H. (2003). The dual-path model of social movement participation: The case of fat acceptance movement. Social Psychology Quarterly, 66, 71-82.

Summer, W. (1906). Folkways. New York: Ginn.

Tajfel, H., \& Turner, J. C. (1979). An integrative theory of intergroup conflict. In S. Worchel \& W. G. Austin (Eds.), The social psychology of intergroup relations (pp. 33-47). Chicago: Nelson-Hall.

Taylor, N., \& McGarty, C. (2001). The role of subjective group memberships and perceptions of power in industrial conflict. Journal of Community \& Applied Social Psychology, 11, 389-393.

Thomas, E. F., \& McGarty, C. (2009). The role of efficacy and moral outrage norms in creating the potential for international development activism through group-based interaction. British Journal of Social Psychology, 48, 115-134.

Turner, J. C. (1982). Towards a cognitive redefinition of the group. In H. Tajfel (Ed.), Social identity and intergroup relations (pp. 15-40). Cambridge: Cambridge University Press.

Turner, J. C., Hogg, M. A., Oakes, P., Reicher, S. D., \& Wetherell, M. S. (1987). Rediscovering the social group: A self-categorization theory. Oxford: Basil Blackwell.

van Zomeren, M., Spears, R., Leach, C. W., \& Fischer, A. H. (2004). Put your money where your mouth is! Explaining collective action tendencies through group-based anger and group efficacy. Journal of Personality and Social Psychology, 87, 649-664.

Wright, S. C. (2001). Strategic collective action: Social psychology and social change. In R. Brown and S. Gaertner (Eds.), Intergroup processes: Blackwell handbook of social psychology (Vol. 4, pp. 409-430). Malden, MA: Blackwell Press.

Wright, S. C., \& Lubensky, I. (2008). The struggle for social equality: Collective action versus prejudice reduction. In S. Demoulin, J. P. Leyens, \& J. F. Dovidio (Eds.), Intergroup misunderstandings: Impact of divergent social realities (pp. 291-310). New York: Psychology Press.

CRAIG MCGARTY is Professor of Psychology and the Director of the Social Research Institute at Murdoch University in Western Australia. He was previously Head of the School of Psychology at The Australian National University. He is the author of Categorization in Social Psychology (Sage, 1999) and editor of The Message of Social Psychology (Blackwell, 1997, with A. Haslam) and Stereotypes as Explanations (Cambridge, 2002, with V. Yzerbyt and R. Spears).

ANA-MARIA BLIUC is a post-doctoral researcher at the University of Sydney (Institute for Teaching and Learning). Her PhD in social psychology from The Australian National University explores the role of identification with opinionbased groups in predicting political involvement in non-activist people in several countries including Australia, Romania, and the Netherlands. Her current central interest is in opinion-based groups, more specifically, in the role played by opinionbased groups in spontaneous collective action and political participation, opinionbased group formation, the use of rhetoric by opinion-based groups' members, and strategies used by these groups to achieve political success. 
EMMA F. THOMAS is completing her $\mathrm{PhD}$ at The Australian National University under the supervision of Craig McGarty and Ken Mavor. Her research focuses on ways to promote action to end poverty and preventable disease in developing countries, in particular by making prochange beliefs and emotional reactions normative for social groups.

RENATA BONGIORNO recently submitted her PhD (through the Australian National University). She moved to Murdoch University in 2007 to take up a position as a Research Associate on the Australian Research Council project, Bolstering Commitment to Positive Social Change through Group-Based Interaction, where she focuses in particular on ways of bolstering commitment to environmental sustainability. Her other major research interest is the persistence of gender discrimination in society and the ways that women can be marginalized through the pervasiveness of gender categorization. 